\title{
A Major Discovery: Durkheim's Bordeaux University Library Loans
}

\author{
Editorial Introduction
}

\section{William Watts Miller}

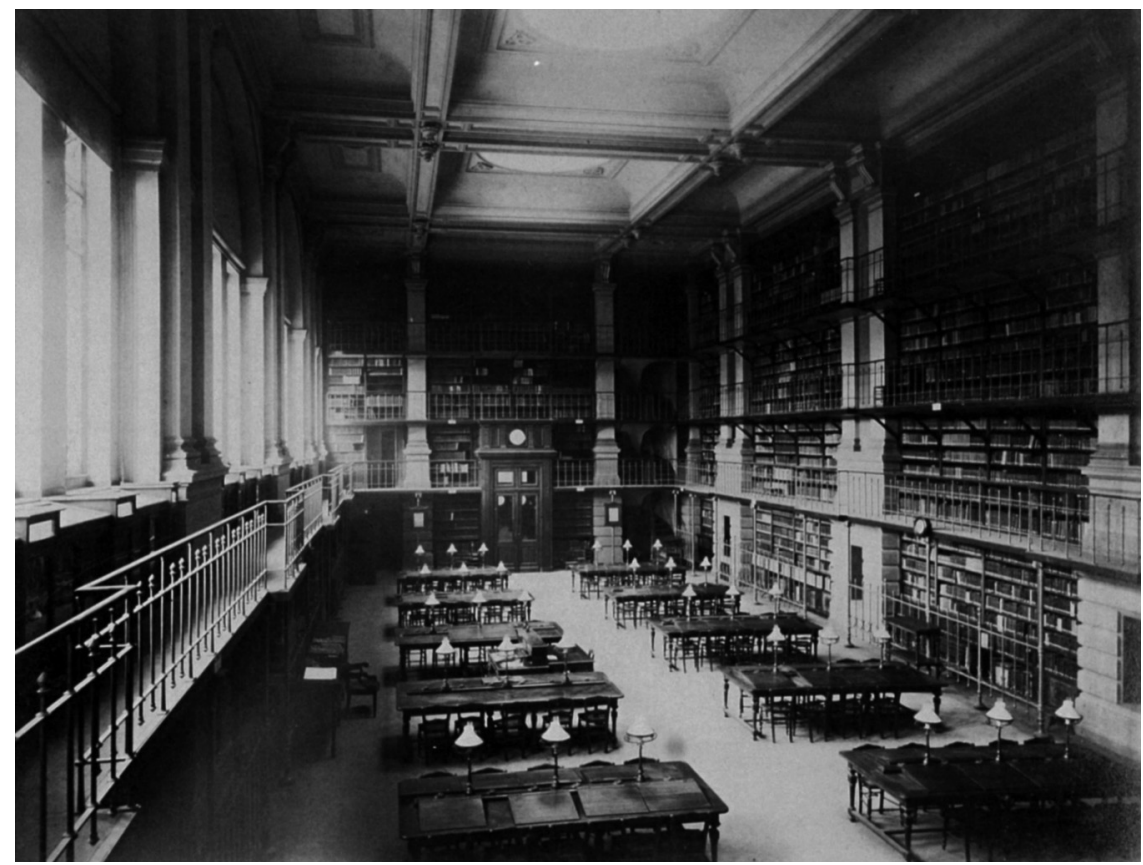

Figure 1. Bordeaux University Arts and Science Library, 1886 (image supplied by Matthieu Béra, from the Album Terpereau, coll. Musée d'Aquitaine)

The discovery of registers recording Durkheim's loans from Bordeaux University's Arts and Science Library, and also his acquisition requests, presents scholars in the field with a vast and at the same time challenging mass of new material. Acknowledgements are due to Nicolas Sembel and Matthieu Béra for their combination of initiative and effort, after the initial discovery's excitement, in looking for similar registers in the university's 
Law and Medical Libraries, but also and not least in combing through the surviving records to work them up into readily accessible documents. In undertaking to publish the fruits of their research in this journal, it has been decided to do so in two stages. The first, in the present issue, consists of the documents themselves together with a commentary, in French, by Nicolas Sembel; this will be followed in the next issue by a commentary, in English, by Matthieu Béra.

No arrangement is perfect. However, this seems as good a way as any of maintaining the journal's commitment to a collaborative mix of Frenchand English-language work, while also making adequate space for commentaries that approach the material through different yet nonetheless overlapping concerns. Thus, Sembel is especially interested in how the loans reveal a 'hidden' Durkheim and how they help with understanding not so much particular works but the development of his overall sociological project, while Béra especially explores how the loans connect not just with Durkheim's publications but also with his many lecture courses over the years, most of which are now lost. In any case, it is clear that what they found in the in the Bordeaux library can help to stimulate further discoveries and open up and advance new lines of research. 